
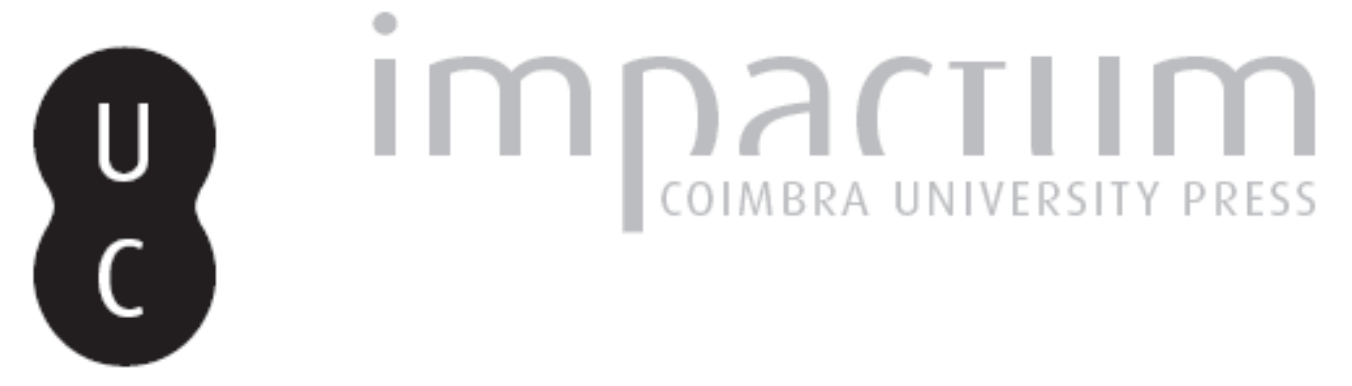

Propuesta de interpretación de Rei D. Afonso, se Deus vos pardom

Autor(es): Kurtz, William S.

Publicado por: Centro de História da Sociedade e da Cultura

URL persistente:

URI:http://hdl.handle.net/10316.2/39384

DOI:

DOI:http://dx.doi.org/10.14195/1645-2259_13_2

Accessed : $\quad$ 26-Apr-2023 12:30:10

A navegação consulta e descarregamento dos títulos inseridos nas Bibliotecas Digitais UC Digitalis, UC Pombalina e UC Impactum, pressupõem a aceitação plena e sem reservas dos Termos e Condições de Uso destas Bibliotecas Digitais, disponíveis em https://digitalis.uc.pt/pt-pt/termos.

Conforme exposto nos referidos Termos e Condições de Uso, o descarregamento de títulos de acesso restrito requer uma licença válida de autorização devendo o utilizador aceder ao(s) documento(s) a partir de um endereço de IP da instituição detentora da supramencionada licença.

Ao utilizador é apenas permitido o descarregamento para uso pessoal, pelo que o emprego do(s) título(s) descarregado(s) para outro fim, designadamente comercial, carece de autorização do respetivo autor ou editor da obra.

Na medida em que todas as obras da UC Digitalis se encontram protegidas pelo Código do Direito de Autor e Direitos Conexos e demais legislação aplicável, toda a cópia, parcial ou total, deste documento, nos casos em que é legalmente admitida, deverá conter ou fazer-se acompanhar por este aviso. 

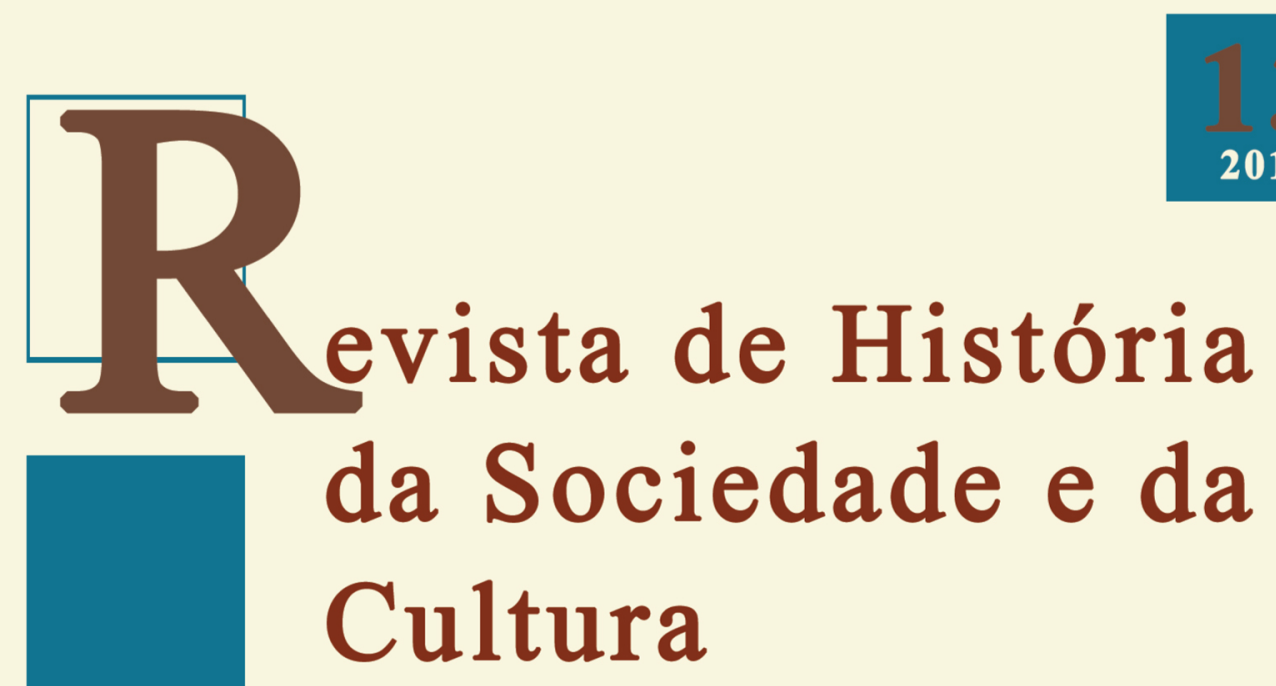

2013

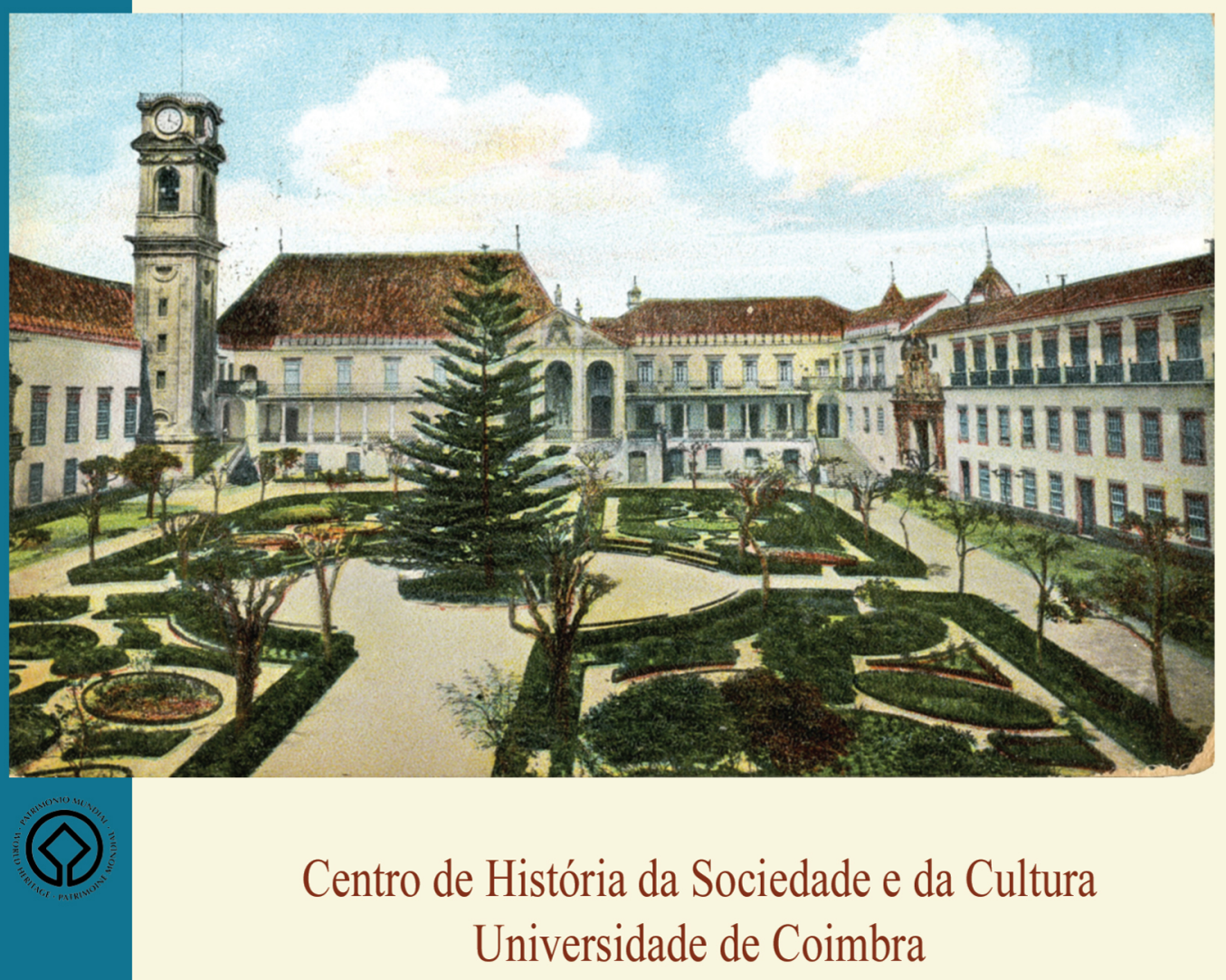

Coimbra 


\title{
Propuesta de interpretación de Rei D. Afonso, se Deus vos pardom
}

\author{
William S. Kurtz \\ Museo Arqueológico Provincial de Badajoz \\ guillermokurtz@hotmail.com \\ Texto recebido em /Text submitted on: 23/05/2013 \\ Texto aprovado em /Text approved on: 19/09/2013
}

Resumo/Abstract:

Se re-examina en este artículo la tenção que mantuvieron Alfonso X y Vasco Gil Rei D. Afonso, se Deus vos pardom, y se plantea una nueva hipótesis para comprenderla.

This article reexamines the tenção, Rei D. Afonso, se Deus vos pardom, written by Alfonso X of Castille and Vasco Gil, proposing a new hypothesis about its interpretation.

Palavras chave/Keywords:

Alfonso X, Vasco Gil; Tenção; Manto.

Alfonso X, Vasco Gil; Tenção; Mantle. 


\section{Introducción}

En 1901 doña Carolina Michaëlis dedicó su segunda Randglosse ${ }^{1}$ a una tenção que mantuvieron don Vasco Gil y Alfonso X. En ella soluciona una parte importante de las cuestiones que tal poema suscita, pero, a mi entender, dejó flecos por resolver. Suficientes como para justificar una nueva aproximación al tema.

El poema en cuestión es:

- Rei D. Afonso, se Deus vos pardom, desto vos venho [a vós] preguntar; [si]quer ora punhade de mi dar tal recado, que seja com razom:

5 quem dá seu manto, que lho guard'alguém, e lho não dá tal qual o deu, por en que manda [i] o Livro de Leon?

- Dom Vaasco, eu fui já clerizom

e Degreda soía estudar;

10 e nas escolas u soía entrar dos maestres aprendi tal liçom: que manto d'outrem nom filhe per rem; mais se o m'eu melhoro, faço bem, e nom sõo por aquesto ladrom.

15 - Rei Dom Afonso, ladrom por atal em nulha terra nunca chamar vi, nem vós, senhor, non'o oístes a mim, ca, se o dissesse, diria mal; ante [o] tenho por trajeitador

20 (se Deus mi valha, nunca vi melhor) quem assi torna pena de cendal.

1 MICHAËLIS DE VASCONCELOS, Carolina - Randglossen zum altportugiesischen Liederbuch: II - Ein Mantel-Lied. Zeitschrift für romanische Philologie. XXV (1901) 139-149. 
- Dom Vaasco, dizer-vos quer'eu al daqueste preito, que eu aprendi: oí dizer que trajeitou assi

25 já ũa vez um rei em Portugal: houve um dia de trajeitar sabor e por se meter por mais sabedor, fez [alguém²] cavaleiro do Hespital.

La tenção es de sobra conocida ${ }^{3}$, y en ella Vasco Gil interpela a Alfonso $X$ con una pregunta: ¿qué dice el Libro de León sobre el caso de alguien que, habiendo recibido de otro un manto para que se lo guarde, no lo devuelve en su estado original?. Don Alfonso, eludiendo mencionar el libro leonés, responde que, habiendo estudiado degreda...nas escolas, aprendió que mejor no recibir manto de nadie, pero que si lo mejora no es por ello un ladrón. Don Vasco responde con indignación que nunca calificó como ladrón a la persona de quien estuviera hablando, es más indica que em nulha terra se le llamaría así, sino que lo considera un trajeitador, posiblemente el mejor de este género, capaz de tornar pena de cendal. Alfonso X remata el poema, y el desarrollo de la cuestión, trayendo a colación un caso similar al que tratan, el de un rey de Portugal que en una ocasión también tuvo ganas de trajeitar, y por ello hizo a alguien cavaleiro do Hespital.

Doña Carolina, en el mismo artículo, relacionó esta tenção con otra, mantenida entre don Vaasco y Pero Martins, en el que el primero interpela al segundo sobre qué miembros de la Orden del Hospital sobresalen en la mentira, la avaricia y la lujuria; Pero Martins responde con nombres, todos ellos identificables, y ambos comentan el tema. Esta identificación permite a la autora ubicar el poema en el entorno de 1252. La aparición en ambas tenções de don Vasco y de la orden hospitalaria es la base para que dicha investigadora estableciera una estrecha relación entre ambas composiciones, aceptada unánimamente por toda la comunidad científica. Es importante notar que el papel de la Orden del Hospital en ambos poemas es muy

2 En el original: fez cavaleiro do Espital; Michaëlis: fez-se; Lapa fez [Foan].

3 En los manuscritos B 1512 (C 1512); publicado en PAREDES, Juan - El Cancionero profano de Alfonso X el Sabio. Edición crítica, con introducción, notas y glosario. Verba, Anexo 66, Santiago de Compostela: Servicio de Publicacións e Intercambio Científico, 2010, $\mathrm{n}^{\mathrm{o}} \mathrm{xliii}$, donde cita toda la bibliografía anterior 
diferente: en la primera cumple un papel secundario, una referencia paralela al tema de que se está tratando, mientras que en la segunda es el objeto y sujeto de la tenção. Con todo esto se quiere resaltar que la relación entre ambos poemas no es tan estrecha como pueda parecer, y que las deducciones que se deriven de una no necesariamente sean aplicables a la otra.

Los flecos pendientes a que se hacía referencia al comienzo de este trabajo, son: de qué están hablando los autores exactamente; el marco jurídico a que están haciendo referencia; la identificación del personaje a quien se confió el manto y que lo devuelve alterado; y el contexto histórico en el que debe ubicarse. En ellos se centrará este trabajo.

\section{EI manto}

Primero, un manto es la excusa para poner en marcha la cuestión, y el centro referencial de todo el poema. Como objeto no presenta problemas de identificación: una prenda exterior que cubría el resto de la ropa, remataba el conjunto de la vestimenta y la completaba como puesta en escena de la persona. Se utilizaba por parte de los diferentes estamentos sociales como demuestra una provisión de las Partidas ${ }^{4}$; y lo mismo valía para hombres como para mujeres. Cuestión aparte es saber si en esta cantiga, o incluso en el conjunto de la poesía galaico-portuguesa, el manto en cuestión está presente como operador, como símbolo. Para determinarlo, será necesario examinar el uso del término en otros poemas.

En lo que respecta al manto como prenda femenina, el caso mas sencillo es el de $A$ por que perço o dormir ${ }^{5}$ de João Airas de Santiago cuyo refram es

4 Se citarán las Partidas y el Espéculo por la edición de la Real Academia de la Historia (Las Siete Partidas del rey don Alfonso el Sabio. Cotejadas con varios códices antiguos por la Real Academia de la Historia. Madrid: Imprenta Real, 1807, 4 vols.). En la Partida II, Título XXI, Ley XVIII (vol II, p. 211-212) en el epígrafe En qué manera se deben vestir los caballeros, el manto es prácticamente la única vestimenta usada como seña de identidad de esta clase social. En la Partida II, Título XXVI, Ley XXXII (vol. II, p. 302-302), al hablar de los fiadores que se constituyen en la subasta del reparto de la almoneda, indica que se les pueden tomar los mantos si no pagan, tanto si son hombres honrados como si fueran "otros hombres", implicando que manto vestirían no sólo los hombres honrados sino también gente de categoría inferior.

5 B960/V547. 
muy claro al respecto, Deus! que bem lh'está manto e saia, donde el manto es el indicador de la belleza de la mujer amada. En Se hoj'o meu amigo de Estevão Coelho ${ }^{6}$, parece que se está indicando sólo la prenda misma. Y estos dos son los únicos poemas de amor y de amigo en los que se menciona esta prenda. Todavía dentro del ámbito femenino, Lopo Lías utiliza dos veces el manto en el ciclo de escarnios dedicados a los infanzones de Lemos ${ }^{7}$, donde el manto (junto con un brial) es la prenda que caracteriza a la fremosa, contrastada con la sela que caracteriza al zevrom ${ }^{8}$.

Como prenda masculina se documenta en nueve ocasiones, casi siempre en un contexto de escarnio; salvo en Nom me posso pagar tanto ${ }^{9}$, atípico sirventés moral de Alfonso X donde hace referencia al manto como uno de los atributos reales a que estaría dispuesto a renunciar. En los contextos de escarnio su uso es el siguiente. En Eu digo mal, com 'home fodimalho ${ }^{10}$ de Pero da Ponte, el manto en primera instancia no es más que la prenda exterior que ha de ser levantada para que el tal fodimalho pudiérale achantar o caralho; es decir, el manto era la prenda que separaba el ámbito público y social de la persona de su ámbito íntimo y sexual. Este carácter de frontera entre lo público y decente con lo impropio está presente también en la mención del manto en las dos instancias en que lo usa Martim Soares en sus escarnios contra Joam Fernándiz (Joam Fernandez, que mal vos talharom ${ }^{11}$ y Joam Fernándiz, um mour 'est aqui $\left.{ }^{12}\right)$ : en el primero la ausencia de manto es el motivo mismo de la crítica (ergo: no está decente y honradamente vestido) y en el segundo se juega con que bajo el manto esconde un mouro, posible alusión a un pene circuncidado.

6 B721/V322.

7 Concretamente en Tercer dia ante Natal (B1339/V946) y Enmentar quer'eu do brial (B1340/V947).

8 El ciclo es extraordinariamente complejo de desentrañar, remito a BELTRÁN, Viçenç - Lopo Liáns "en cas da ifante". Medievalismo en Extremadura: estudios sobre literatura y cultura hispánicas en la Edad Media, coord. por Jesús Cañas Murillo, Francisco Javier Grande Quejigo, José Roso Díaz. Cáceres, 2009, p. 305-312 y SOUTO CABO, José António - Lopo Lias: entre Orzelhão e Compostela. Diacrítica. 25.3 (2011) 111-136.

9 B480/V63.

${ }^{10} \mathrm{~B} 1626 / \mathrm{V} 1160$ (C 1626).

${ }^{11} \mathrm{~B} 1370 / \mathrm{V} 978$.

${ }^{12}$ B1367/V975. 
Un caso claro en el que el manto es un claro indicador de posición social es Chegou Paio de más artes ${ }^{13}$ de Pero Mendes da Fonseca: un hombre rafez pasa de tener ropas pobres (cerame de Chartes) a tener manto com espada, en un contexto donde se critica la rápida ascensión del personaje ${ }^{14}$.

En lo que respecta al manto en los poemas profanos de Alfonso X, ya se ha comentado el caso de Nom me posso pagar tanto. En De grado queria ora saber ${ }^{15}$ el rey critica toda la vestimenta de un grupo de personas que, entre otras cosas, llevan mal el manto. En Dom Gonçalo, pois queredes ir daqui pera Sevilha ${ }^{16}$ el manto es simplemente una prenda que puede perder el destinatario del poema, pero dado que el tono del poema es una explícita amenaza a Gonzalo Eanes do Viñal ${ }^{17}$, puede entenderse que la posibilidad de perder el manto signifique el peligro de perder su posición social. Más problemática es la cantiga $O$ que da guerra levou cavaleiros ${ }^{18}$ donde la expresión utilizada en su verso 35 es e a sa terra ar foi armar manto. La expresión exacta permitiría pensar que se está refiriendo a una máquina de asedio ${ }^{19}$, aunque la estructura del poema exige que este verso sea una alusión directa de cobardía o de molicie vital, con lo que cabe interpretar que los caballeros cobardes fueron a su tierra a presumir de su vestimenta. El problema es el verbo armar, que no encuentro utilizado en el contexto de la vestimenta, y apunta más bien a la interpretación poliorcética en línea con lo dicho en el verso 45 (macar em Burgos fez pintar escudo),

${ }^{13} \mathrm{~B} 1600 / \mathrm{V} 1132$ (C 1600).

${ }^{14}$ Fuere o no Pelay Pérez Correia (ver LÓPEZ FERNÁNDEZ, Manuel - Apuntes sobre el autor y el protagonista de una cantiga "d'escarnho e de mal dizer". Espacio, Tiempo y Forma, Serie III, H. ${ }^{a}$ Medieval. 17 (2004) 293-304.

${ }^{15} \mathrm{~B} 492 / \mathrm{V} 75$.

${ }^{16}$ B466 (C 467). Parece que nadie haya observado que el itinerario mencionado en el poema aquí-Lebrija-Alcalá-Sevilla demuestra claramente que el tal aquí estaba al sur de Sevilla, lo que tiene obvias consecuencias en la fechación (y por tanto, contexto histórico) del poema.

${ }^{17}$ MAGÁN ABELLEIRA, Fernando; RON FERNÁNDEZ, Xosé Xabier - Algunhas consideracións ecdóticas e hermenéuticas sobre a cantiga "Don Gonçalo, pois queredes ir daqui pera Sevilha" (B 466) de Alfonso X o Sabio. Revista de poética medieval. 3 (1999) 131-146.

${ }^{18}$ B496/145bis/V79.

19 PAREDES NUÑEZ, Juan - Armar manto: algunas consideraciones sobre la cantiga 'O que da guerra levou cavaleiros de Alfonso X'. Revista de filología románica. 14, vol. 1 (1997) (Memoria-homenaje a Pedro Peira Soberón), 569-574. 
en el sentido de que la excusa fuese la de suministrarse en retaguardia (y por tanto, ponerse a salvo). No obstante, prefiero la explicación más sencilla, la de que los caballeros cobardes fueron a su tierra a pavonearse.

En general, el uso del manto como referencia en la poesía galaico-portuguesa apunta al carácter simbólico de la representación social de las personas, al ser el indicador del límite entre lo público y lo íntimo, lo honrado (apropiado) y lo indecente o chocante; y sólo en algunas ocasiones explícito símbolo de posición social.

El manto en sí mismo es una ropa más, y quizá convenga examinarlo brevemente en el conjunto de esta literatura, pues la IV Randglosse en que la trató Carolina Michaëlis ${ }^{20}$ sólo roza la superficie de tan sugerente tema. Se hace mención de ropa en ciento tres cantigas, menos de una décima parte del total; compuestas por cuarenta y siete autores, menos de una tercera parte de la nómina de autores conservados; y utilizando (al menos) setenta y siete palabras referidas a este campo de significación, no demasiadas. Cantigas que traten o mencionen la ropa aparecen en todas las épocas de esta literatura y en todos sus géneros.

Alfonso $X$ fue el poeta que más referencias hizo a ropa y vestimenta en su obra, tanto en número de cantigas, trece ${ }^{21}$, como en riqueza de vocabulario, veintisiete palabras. No fue el poeta que más referencias textiles utilizó en un solo poema, lo hizo Afonso Lopes de Baião en Sedia-xi Dom Belpelho em ua sa maison ${ }^{22}$ en el que inserta trece palabras de este ámbito. Conviene señalar que Afonso Lopes de Baião es el poeta que sigue en frecuencia de uso de este vocabulario a Alfonso $\mathrm{X}$, aunque utilice sólo la mitad de palabras que el rey, bien que en un solo poema.

Resulta imposible examinar todas las cantigas para delimitar el sentido en que usan literariamente las referencias a vestimenta, por lo que se tratará sólo una selección. En ocasiones el uso es descriptivo, como en el ya mencionado

${ }^{20}$ MICHAËLIS DE VASCONCELOS, Carolina - Randglossen zum altportugiesischen Liederbuch: IV- Pennaveira. Zeitschrift für romanische Philologie. XXV (1901) 167-174.

${ }^{21}$ B496/145bis/V79, B458, B492/V75, B466 (C 467), B464, B495/V78, B480/V63, B491/V74, B485/V68, B463, B483/V66, B479/V62, B465 (con García Pérez) y B1512 (C 1512) (con Vasco Gil).

${ }^{22}$ B1470/V1080 (C 1470); comentada en VENTURA, Leontina e OLIVEIRA, António Resende de - Os Briteiros (Séculos XII-XIV) 3. Imagens literárias. Revista Portuguesa de História. XXXV (2001-2002) 148 ss. 
poema de João Airas de Santiago; en otras es un testimonio de un don de amor, como en la cantiga de amigo de don Dinís De que morredes, filha, a do corpo velido? ${ }^{23}$. En la mayor parte de las ocasiones aparece en contextos de escarnio o maldecir. Esto quedaba claro en Sedia-xi Dom Belpelho em ua sa maison, en el que todas las prendas de vestir se utilizan para satirizar la pobreza de las huestes del tal dom Belpelho y, sobre todo, para resaltar su inadecuación al rango social que pretende ocupar. Es, claramente una sátira de clase, en el que la vestimenta y el equipamiento es el indicador principal utilizado, en el que la pobreza es todo lo contrario de la riqueza, largueza y ostentación, cualidades exigibles en un noble poderoso, ricohombre o que aspira a serlo. Es un ejemplo arquetípico, suficiente como ejemplo, aunque podrían aducirse otros, como las satiras contra infanzones de Lopo Lías.

Como se ha dicho, Alfonso X es el poeta galaico-portugués que más usa vocabulario relacionado con la ropa y el contexto textil. En sus poemas la ropa y la vestimenta siempre definen la condición social de las personas. Esto en lo que toca a los poemas de autoría individual del rey; la perspectiva es similar al examinar la otra tenção que sostuvo García Pérez ${ }^{24}$. En ella, el poeta interroga al rey sobre porqué va vestido pobremente, él que habitualmente tan bien vestía. A pesar de lo que pudiera parecer en una primera lectura, no están hablando exactamente del ropaje del rey sino de su realeza misma y poder. La clave para esta interpretación la aporta una norma de las Partidas, con la muy significativa rúbrica Que el rey se debe vestir muy apuestamente ${ }^{25}$, cuya claridad exime de más comentario. La ropa está identificando al personaje en cuanto ser social, en cuanto a posición y categoría. No es fácil encontrar razones que expliquen el porqué Alfonso X es el poeta que más utiliza las referencias a ropa, tanto en vocabulario como en poemas, pero sí está claro que para él tales referencias son una manera de denotar, cuando no denostar, la adscripción social de las personas de las que trata en su obra profana.

Más arriba se planteó la interrogación de si, en esta cantiga, el manto en cuestión está presente como operador, como símbolo. Visto lo visto

\footnotetext{
${ }^{23} \mathrm{~B} 567 / \mathrm{V} 170$.

${ }^{24}$ B465.

${ }^{25}$ Partida II, Título V, Ley V (vol. II, p. 28-29).
} 
hasta aquí y cómo utiliza las alusiones a la ropa el mismo rey en su poesía, no resulta difícil mantener que en este poema el manto del que están hablando los participantes en la tenção es un símbolo, un significante de clase y, por tanto, de poder.

Ha quedado claro que el manto era una prenda que utilizaban tanto hombres como mujeres de más de una clase social y también un signo identitario de clase. Mas es también necesario resaltar que se usó también como símbolo específico de la realeza, de lo que un ejemplo es el citado poema Nom me posso pagar tanto, y se confirma en el Castigos y Documentos de Sancho IV, en cuyo decimoprimer capítulo (De cómmo deue ser omne armado de armas para se defender) se desarrolla una larga y detallada exposición de lo que significaba el manto del rey como atributo necesario de la representación de su poder. Capítulo que desarrolla la idea ya expresada por su antecesor en el cargo, en la citada rúbrica de la Segunda Partida. Lo que es especialmente interesante del texto sanchista es que como atributo específico del manto real indica... la forradura deste rey eran peñas blancas armiñas, por la qual se demuestra la linpieza que el rey deue auer en la su alma y non la ensuziar en malos fechos njn en malos cuydados.... ${ }^{26}$. El manto del rey tenía, dentro de su riqueza, tales penas como distintivo. Ello no quiere decir que la pena en sí misma fuera distintivo exclusivo del manto real ${ }^{27}$, sino que la decoración del manto real era tan rica que requeriría el uso de penas.

Esta asociación entre manto, realeza y penas es muy sugerente en cuanto a la posibilidad de aplicarla al análisis de esta tenção, toda vez que trata de un manto, y un manto al que se le ha cambiado el cendal para convertirlo en pena. En tal sentido, cabe la posibilidad de que el manto que dió origen al poema fuera el manto real, un símbolo del poder del rey.

${ }^{26}$ Edición en RIVERA GARCÍA, Antonio - Manuscrito B de Castigos y Documentos para Bien Vivir de Sancho IV, Ed. de Antonio Rivera García según el Manuscrito B (ms. 6603 de la Biblioteca Nacional de Madrid, s. XV, 118 ff.), Biblioteca Saavedra Fajardo (http:// saavedrafajardo.um.es/WEB/archivos/LIBROS/Libro0441.pdf, consultado en 2013.03.21), p. 57.

${ }^{27}$ Son varias las cantigas, aparte de ésta, que citan penas o penas veiras en este sentido textil de la palabra (casi tantas como aquellas que lo usan en el sentido de pena/dolor). Remito a la citada IV ${ }^{\mathrm{a}}$ Randglosse. 


\section{EI contexto jurídico del poema}

En la primera estrofa, Vasco Gil plantea una cuestión al rey y quiere saber qué establece al respecto el Livro de León. Por ello, conviene determinar a qué se refiere al hablar de tal Livro. Desde el artículo de doña Carolina al presente se ha entendido que podría aludir al Fuero de León dado por Alfonso V hacia $1020^{28} \mathrm{o}$ al Fuero Juzgo, que generalmente, y simplificando, se entiende como la base del derecho del reino leonés. Mas en ninguno de estos dos instrumentos jurídicos hay mención alguna al tema que plantea la tenção, o paralelizable siquiera. Con lo que es difícil considerar que se estuviera refieriendo a ninguno de estos dos livros. No obstante, es necesario plantear que el poeta tuviera en mente un corpus jurídico concreto, conocido o reconocible por todos, siquiera sea porque de lo contrario carecería de sentido la interpelación que planteó. En tal dirección apunta el hecho de que en otra cantiga aparezca otra vez la misma formulación, Livro de León, referido a un corpus legal normativo.

Se trata de Ai Justiça, mal fazedes, que nom ${ }^{29}$ de Johan Airas de Santiago ${ }^{30}$, un autor posterior al de la cantiga aquí examinada, en el que demanda justicia de Mor de Cana, que ha matado de amor a Johan Airas ${ }^{31}$ y por tanto... se dereito queredes fazer, / ela sô el devedes a meter, / ca o manda o Livro de Leon. La broma se articula sobre una maliciosa interpretación de una antigua pena legal, que estipula que (según las circunstancias) qui homine occiderit vivus sub eo sepeliatur (en romance: qui matare a otro, métanle so el muerto). Esta disposición sí puede rastrearse en los distintos repertorios legales y por tanto puede ilustrar sobre la naturaleza del Livro. Para empezar, no aparece ni en el Fuero de León ni en el Fuero Juzgo, confirmando que no son estos los livros a que se refirieron Vasco Gil y Johan Airas.

Esta modalidad concreta de castigo aparece en diversos fueros municipales dados entre la segunda mitad del siglo XII y la primera del XIII en los reinos de Aragón, Castilla, León, Portugal, y en Béarn y Bigorra, como son, a título

${ }^{28}$ ANÓNIMO - Cortes de los Antiguos Reinos de Castilla y León publicadas por la Real Academia de la Historia, Volumen I, Madrid: Imp. Rivadeneyra, 1861.

${ }^{29}$ B1466/V1076.

${ }^{30}$ Aproximadamente 1270-1295.

${ }^{31} \mathrm{Si}$ el mismo poeta o un homónimo, no es cuestión. 
de ejemplo ${ }^{32}$ : Teruel, Cuenca, Villafranca del Bierzo, Mayorga de Campos, Alcaraz, Zorita de los Canes, Baeza, Sepúlveda, Plasencia, Béjar, Bayona, Sanabria, Lourinhã, Marmelar, Morlas (Bearn) y Bigorra. Muchos de estos fueros son de la familia Teruel-Cuenca, mas no todos, y no todos los fueros de dicha familia contienen este castigo. En general se especifica que debe aplicarse en aquellos casos en los que existe propincuidad o familiaridad entre víctima y homicida, pero no siempre. A pesar de la aparición de esta disposición en Du Cange ${ }^{33}$ y en Grimm ${ }^{34}$, parece tratarse de una costumbre peninsular al no aparecer en disposiciones de otras áreas políticas, y la aparente internacionalidad de tal inclusión deriva de que la fuente única de estos autores son las disposiciones bearnesas ${ }^{35}$, otorgadas por señores de origen catalano-aragonés ${ }^{36}$.

La disposición invocada por Johan Airas de Santiago, aparece una vez en el Espéculo de Alfonso $\mathrm{X}^{37}$, y otra en las Partidas ${ }^{38}$. Antes de tratarlo, conviene examinar un detalle de especial interés, cual es la siguiente afirmación del mismo Alfonso $\mathrm{X}$ en el punto cuarto de su romanceado

${ }^{32}$ Aclarar en profundidad este tema exigiría un amplísimo estudio, pues las formulaciones son varias y su complejidad enorme. No es el objetivo de este trabajo.

${ }^{33}$ DU CANGE - Glossarium mediae et infimae latinitatis, s.v. Sepeliri (http://ducange. enc.sorbonne.fr, consultado 2013.05.5).

${ }^{34}$ GRIMM, Jacob - Deutsche Rechts Alterthümer. Göttingen: Dietrerichschen Buchhandlung, 1828, p. 694.

${ }^{35}$ MARCA, Pierre de - Histoire de Bearn. Contenant l'origine des rois de Navarre, de Ducs de Gascogne, Marquis de Gothie, Princes de Bearn, Comtes de Carcassone, de Foix et de Bigorre. Paris: chez la Veuve Jean Camusat, 1640, p. 338.

${ }^{36}$ Una nota de caución: la llamada justicia popular es compleja e irracional. La posibilidad de múltiples e independientes orígenes, reapariciones o meras coincidencias no debe minusvalorarse. Un ejemplo, muy reciente, tan parecido a la disposición medieval del que se está hablando que da miedo, máxime al haberse producido en otro continente, avalado por legislaciones pro-indigenistas que reivindican la validez y autenticidad de lo popular y tradicional por encima de lo racional y convencional: (relato de un linchamiento ocurrido en Bolivia) "La.... víctima mortal fue el joven Santos Ramos, de 17 años y natural de Colquechaca, identificado como el presunto violador y asesino de una indígena quechua -como él- de 35 años. Según el relato de la cadena de radio Erbol, Ramos fue identificado durante los funerales. Fue detenido y golpeado y posteriormente, con las manos atadas a la espalda y boca abajo... lanzado a una fosa antes de colocar encima de él el ataúd con los restos de su supuesta víctima". EL PAís, 8 de junio, 2013 (edición impresa, p. 8).

${ }^{37}$ Espéculo, Libro III, Título VIII, Ley IV (Vol. I, p. 123), aplicable sólo en el caso de cavalgadas.

${ }^{38}$ Partida II, Título XVI, Ley III, reservado sólo a minores. 
y confirmación del fuero de Sanabria, en 1263: E lo que dice en el otro privilegio que matador fuese metido so el muerto, esto non tenemos por guisado $^{39}$. Este no tenerlo por guisado es muy coherente con la labor legislativa alfonsina, con su intento de racionalizar el derecho y alejarlo de la consuetudinariedad tradicional. Recordemos que, por ejemplo, esta pena de muerte concreta está ausente del Fuero Real y que en el Espéculo y en las Partidas se limita su aplicación a casos muy concretos. Teniendo además en cuenta la fecha del comentario al fuero sanabrés, posterior a la redacción del Espéculo y del Fuero Real, y casi contemporánea a la elaboración de la primera Partida ${ }^{40}$, puede apreciarse la evolución dentro del pensamiento legal del rey. En la misma tenção aquí analizada está clara dicha evolución, con lo que puede interpretarse como una toma de postura explícita del rey: al contestar a Vasco Gil en la segunda estrofa, directamente manifiesta que él fue clerizóm e degreda soía estudar. Es fácil entender que está tomando partido por el recuperado derecho romano enseñado nas escolas.

En la tensó aquí estudiada existe también una referencia al Espéculo, en este caso menos directa. En su tercera estrofa, escrita por Vasco Gil, para rematar la cuestión y resaltar la calificación de trajeitador aplicado a la persona anónima a quien se cedió el manto y lo devolvió alterado, usa la expresión quem assi torna pena de cendal. Cendal que formaba parte del manto, y que dicha persona convirtió en pena. La asociación entre manto y cendal establecida en esta tenção aparece en dos de los artículos del Espéculo, en las leyes octava y novena del Título VII del Libro $\mathrm{V}^{41}$ :

- ley VIII.... aquel a qui demandan la cosa, maguer la tenga en su poder, nol pueden dezir senaladamiente tenedor della, porque aquella cosa es ayuntada con otras cosas, e pierde aquél nonbre señalado que avie, por razon que es ayuntada a otra cosa, que es mayor o mejor que ella de que gana el nonbre, e pierde el que ante avie. E esto serie,

${ }^{39}$ FERNÁNDEZ DURO, Cesáreo - El fuero de Sanabria. Boletín de la Real Academia de la Historia. 13 (1888) 281-291.

${ }^{40}$ CRADDOCK, Jerry R. - La cronología de las obras legislativas de Alfonso X el Sabio. Anuario de Historia del Derecho Español. 51 (1981) 365-418: Espéculo concluido en 1255; Fuero Real concedido en 1256; tres redacciones de la Primera partida, la primera realizada entre 1256 y 1265, las dos últimas posteriores a 1272.

${ }^{41}$ Espéculo, Libro V, Título VII, Ley VIII-IX (p. 342). El ejemplo manto-cendal reaparece nuevamente en la Partida III, Título II, Ley XVI (Vol. II, p. 362). Subrayados míos. 
como si alguno metiese cendal ageno en su manto. Ca después quel y oviese metido, nol dizen cendal sinon manto.

- ley Ix: Ayuntadas seyendo dos cosas en uno, asi como piedra preciosa en oro ageno, o un cendal con otro o con paño...

Dicho título está dedicado a temas de derecho procesal civil, y cuya rúbrica general De las demandanzas e de las respuestas por que se comienzan los pleitos es relevante al tema del poema, que empieza con el planteamiento inicial de una cuestión (versos cuarto y quinto) y la petición por parte de Vasco Gil de saber qué establece al respecto la normativa (Livro de León), y por tanto el poema puede entenderse como una demandanza $a^{42}$. Cláudio Neto compara la estructura del poema con el método escolástico de la quaestio, disputatio et quodlibet. Esta forma de definir la estructura no contradice, más bien complementa, lo dicho ${ }^{43}$.

En los mencionados artículos del Espéculo, el ejemplo manto-cendal se utiliza como un caso particular de tignum iunctum, concepto jurídico que tiene su base en la sexta de las Doce Tablas y un amplio desarrollo en el código justinianeo, pero donde no aparece específicamente este ejemplo para ilustrar el concepto. No es cuestión aquí de entrar en el complejo y especializado tema del derecho romano medieval y las fuentes utilizadas por el equipo alfonsí, pues ya queda claro que la tenção está relacionada con el ámbito de su interés por la implantación del derecho romano, no sólo por sus referencias explícitas sino también por su misma estructura.

Resultaría tentador postular que estas referencias poéticas al Livro de León, añadidas a la literalidad del prólogo del Espéculo ${ }^{44}$, apuntaran a la existencia de una recopilación de derecho leonés, similar a las conservadas

${ }^{42}$ Definida en la ley primera del mismo libro y título del Espéculo: Demandanza de las cosas es en dos maneras. Ca la una se faze en razón del señorio de aquella cosa misma que demandan, e la otra en razón de la tenencia délla...

${ }^{43}$ NETO, Cláudio André Conceição do Nascimento - As Ordens Militares na cultura escrita da Nobreza - 1240-1350. Representações nas cantigas de escárnio e de mal dizer, Dissertação de Mestrado em História Medieval, Faculdade de Ciências Socias e Humanas, Universidade Novea de Lisboa, Lisboa, 2012 (http://hdl.handle.net/10362/8646), p. 24.

${ }^{44}$ Espéculo (vol. I, p. 2): catamos e escogiemos de todos los fueros lo que mas valie e lo meior e pusiemoslo, y tan bien del fuero de Castiella, como de León, como de los otros logares que nos fallamos que eran derechos. 
para Castilla ${ }^{45}$, pero afirmarlo tajantemente sería excesivo con los datos disponibles ${ }^{46}$. Pues es igualmente posible interpretar que el tal Livro de León no sea más que un recurso literario, que no se refiera específicamente a una obra jurídica concreta, sino que fuera (en ambos poemas) un operador literario, una forma abreviada de referirse a las antiguas leyes, complejas y confusas, consuetudinarias y arcaicas que el rey Alfonso X pretendía sustituir por otra legislación más actualizada y acorde con sus intereses políticos.

\section{Un rey trajeitador en Portugal, y la Orden del Hospital}

Siguiendo con el curso del poema (verso 13), el rey especifica que si el manto en cuestión se mejora, no se es por ello ladrón, a lo que Vasco Gil responde que él no aplicó jamás dicha calificación, que de ninguna manera es de aplicación...ca, se o dissesse, diria mal. Está claro que, hablara de lo que hablara, hablara de quien hablara, no estaba pensando en robo alguno, sino que pasa seguidamente a calificarle como trajeitador en grado sumo, capaz de convertir cendal en pena.

El término trajeitador es complejo y ha sido tratado extensamente por el profesor Gutiérrez Cuadrado ${ }^{47}$ :

"TRESGITEOR se documenta entre los siglos XII y XV en «phrasal combinations with jooresses, joeors, tumeresses, jugleor, and menestrier.... TRASGITAR y TRASGITADOR (a. prov.) aparecen relacionados sintagmáticamente con TRAGETTEURS, con juglares y timadores. De particular relevancia para nosotros es el testimonio

${ }^{45}$ A título de ejemplos: el Fuero Viejo de Castilla (JORDÁN DE ASSO Y DEL RÍO, Ignacio e MANUEL Y RODRÍGUEZ, Miguel de - El Fuero Viejo de Castilla. Madrid: Imprenta de Joachin Ibarra, 1771) o el Libro de los Fueros de Castiella (SÁNCHEZ, Galo - Libro de los Fueros de Castiella, Barcelona, 1924).

${ }^{46}$ Siguiendo con el planteamiento de no desarrollar todos los temas que se plantean a lo largo del discurso, salvo aquellos específicos que atañen al poema aquí analizado, no se pretende analizar todas las referencias legales posibles en las cantigas profanas, que son varias. Por ejemplo, Airas Peres Viutorom (B1484/V1096), Afonso Anes de Cotom (B1581/ /V1113) y Pay Gómez Chariño (B1624/V1158 (C1624) hacen mención a un foro de León; y João Servando (V1028 (C1419)) menciona el for de Castela. Las menciones al ámbito leonés son mucho más numerosas que al castellano.

${ }^{47}$ GUTIÉRREZ CUADRADO, Juan - Ángeles Tragetados (Sacrificio de la Misa, 13a). Voces. 3 (1992) 31-54. 
del siglo XV que «in the argot of the coquillarts explains that TRESGETEURS are those who rob people by changing gold into money and money into gold... TRESGETERIE - puntualiza Morgan- parece apuntar específicamente «to magic». TRESGETER «lends itself to several translations; usually it means 'to melt', 'to pour into a mould' and refers to metal or an object made of metal»"

En origen el término no tiene nada que ver con la farullería, pues el término tresjeitar en sí mismo tiene el significado de "transformar", convertir algo en lo que no era en principio. El que adquiriera el sentido negativo es un reflejo más de la escasa estima que en las sociedades tradicionales (donde las cosas han de ser lo que son y alterar su esencia es un ataque al buen orden del universo) tiene el sector secundario de la economía dedicado sobre todo a la transformación, frente a los sectores primario (laboratores) y terciario (bellatores y oratores).

Introducida la calificación de trajeitador, don Alfonso remata la tenção haciendo una apreciación sobre aqueste preito, expresión que no deja lugar a dudas de que el poema trata de un tema específico. Sobre dicha calificación establece el rey un paralelismo entre aquello de que está tratando con Vasco Gil y lo que ja ũa vez hizo um rey em Portugal quien trajeitou assi. Así, con esa palabra, no queda duda sobre la identidad entre las dos situaciones. Identificar esta última referencia puede ser una ayuda para entender el conjunto del poema.

Como primera observación, debe notarse que dice UM rey no O rey de Portugal. En cualquier caso, el artículo demuestra que el rey al que se refiere estaba muerto cuando se escribió el poema, lo que excluye a don Dinís, pero no imposibilita que fuera cualquiera de sus antecesores; aunque la expresión utilizada por el monarca castellano-leonés, oí dizer, apunta más bien a los tres primeros reyes de Portugal. Fuera el rey que fuera, fez [alguém] cavaleiro do Hespital, último verso y remate por tanto del poema.

La deficiente conservación de este último verso impide saber a quién $f e z$ tal rey cavaleiro do Hospital. Si faltaran dos sílabas para completar la medida

${ }^{48}$ A lo que se puede añadir que en las Etimologías Romanceadas de San Isidoro se define a pugillator como aquel que de la una mana a la otra furta algund dinero e es manera de tragetar (GONZÁLEZ CUENCA, Joaquín - Las Etimologías de san Isidoro romanceadas. Salamanca: Institución Fray Bernardino de Sahagún, 1983, vol. I, p. 403). 
del verso, cabría cualquier interpretación y sobrarían comentarios; aunque, de admitir que sólo parece faltar una sílaba ${ }^{49}$, caben tres posibilidades, todas pronombres: le, se y vos $^{50}$.

- en el primer caso, la referencia sería la innominada persona de quien se está hablando a lo largo de la tençó.

- en el segundo, el elegido por Michäelis, sería necesario encontrar un rey portugués que fuera caballero de esta $\operatorname{Orden}^{51}$.

- el tercero lanzaría sobre Vasco Gil toda la chacota del rey Alfonso, y está en la línea de la interpretación de Neto ${ }^{52}$ de que Sancho II pudo haber dado el manto sanjuanista a Vasco Gil, siendo un problema el que no conste la pertenencia del noble a dicha milicia.

La mención a la Orden de San Juan del Hospital de Jerusalén exige comentar las varias citas a dicha orden en las cantigas profanas galaico-portuguesas, todas invariablemente negativas. En la literatura académica se suele entender ${ }^{53}$ que estas menciones y cantigas conforman un ciclo con significación propia en el que se estaría criticando la postura de dicha orden en los acontecimientos que abocaron al exilio de Sancho II de Portugal. Es una hipótesis poco defendible. Menciones a la orden hospitalaria aparecen en la obra de cinco poetas: Pero Martinz (1228-1260), Vasco Gil (1238-1258), Caldeiron (1239-40), Gonçalo Eanes do Vinhal (1243-1285), Alfonso X (1252-1284), y Gil Perez Conde (1269? 1282-1286). Está claro que al menos dos de estos poetas difícilmente coincidieron con la guerra civil portuguesa de 1246-1248. Caldeiron, es anterior a los hechos supuestamente criticados o muy posterior ${ }^{54}$, y Gil Pérez Conde, es con seguridad muy

${ }^{49}$ Opción tomada por dña. Carolina Michaëlis, loc. cit.

${ }^{50}$ Descarto los pronombres me y nos, por carecer de sentido el verso de usarlos.

${ }^{51}$ Circunstancia difícil de documentar.

52 NETO - As Ordens..., cit., p. 27.

${ }^{53}$ Dos ejemplos que remiten a más bibliografía sobre el tema: OLIVEIRA, António Resende de - Trovadores portugueses nas corte de Afonso X en O trovador galego-português e o seu mundo. Lisboa: Editorial Notícias, 2001, p. 119; y VÍÑEZ SÁNCHEZ, Antonia Las poesías del trovador don Gonçal'Eanes do Vinhal. Cadiz: Servicio de Publicaciones de la Universidad, 2005, p. 53 y nota 109.

${ }^{54}$ Para la cronología de Caldeiron: RON, Xabier - Carolina Michaëlis e os trobadores representados no Cancioneiro da Ajuda, en BREA, Mercedes (coord.) - Carolina Michaëlis e o Cancioneiro da Ajuda, hoxe. Santiago de Compostela: Centro Ramón Piñeiro, 2005, p. 181. 
posterior $^{55}$. El resto pudieran haber sido testigos de la acción hospitalaria en la guerra contra Sancho II. Mas los extremos cronológicos imposibilitan considerar homogéneo el ciclo como tal y el que todos estos autores se refieran a la guerra entre Sancho II y su hermano Alfonso de Boulogne. Desde esta perspectiva, una referencia a la Orden del Hospital no sirve ya como elemento de fechación.

El que todas las menciones a la orden concuerden tanto en el sentido como en la forma y que el tema aparezca con cronologías distantes entre sí, exige encontrar alguna interpretación que trascienda el tiempo. Máxime cuando esta orden en concreto es la única de las de su época que fuera objeto de escarnio en la poesía profana galaico-portuguesa, a la par que, con diferencia, la más mencionada ${ }^{56}$. El tema requeriría un estudio específico, que alargaría en exceso este trabajo, pero hay que considerarlo siquiera brevemente. La razón debió estribar en algún rasgo interno de la propia Orden que la diferenciase de los demás, al menos a ojos de sus contemporáneos.

Por una parte, la Orden hospitalaria tuvo en estos años una importante presencia económica y política, además de excelentes relaciones con al menos parte de la nobleza ${ }^{57}$; mas por otra, está claro que (en palabras de Barquero Goñi) "el reinado de Alfonso X constituye un periodo en el que se observa una brusca detención en el ritmo de desarrollo de las posesiones castellanas del Hospital"58. Igualmente, la posición de la Orden de San Juan en la guerra civil portuguesa favorable a Alfonso de Boulogne, en línea con lo ordenado al respecto por el papado, debió suscitar como mínimo suspicacia en el muy gibelino Alfonso X; cuyas propias relaciones con los

${ }^{55}$ Su poema Ben sabedes, senhor Rei (B1532), a pesar de haber sido asignado a diferentes momentos es necesariamente posterior a la coronación en Toledo de Sancho IV en mayo de 1284 y por tanto sólo tiene sentido en el contexto de la guerra de 1282-1285 entre el Infante Sancho y su padre Alfonso X.

${ }^{56} \mathrm{NETO}$ - As Ordens..., cit., estudia todas las cantigas relativas a órdenes militares.

${ }^{57}$ BARQUERO GOÑI, Carlos - Los Hospitalarios y la nobleza castellana-leonesa (siglos XII-XIII). Historia. Instituciones. Documentos. 21 (1994) 13-40; IDEM - Relaciones de la Orden de San Juan con las otras órdenes militares en Castilla y León (siglos XII y XIII), Norba. Revista de Historia. 22 (2009) 145-157.

${ }^{58}$ BARQUERO GOÑI, Carlos - Los Hospitalarios castellanos durante el reinado de Alfonso X (1252-1584). Alcanate. 2 (2000-2001) 151-162. El autor citado lo considera signo de una reorganización hospitalaria de sus posesiones, no indicio de alejamiento entre el rey y la orden. 
Papas eran complejas y conflictivas ${ }^{59}$. De hecho, no debieron ser excelentes las relaciones entre el rey y la orden cuando ésta apoyó tan contundentemente la rebelión del infante Sancho de 1282, manteniendo su postura incluso en contra de la posición de Martín IV. Nada de esto demuestra un alejamiento entre el rey y la orden, bien que apunta en tal sentido. El hecho definitivo es que en la poesía profana galaico-portuguesa las menciones explícitas a los sanjuanistas son siempre negativas.

Una posibilidad, sugerida por el poema de Caldeirón Os d'Aragom, que soem donear ${ }^{60}$, cuyo texto se articula en general sobre la cobardía, es tener en cuenta que esta orden fuera, de todas, la menos comprometida militarmente en la Reconquista ${ }^{61}$, teniendo como principal objetivo de su presencia en la Península el envío de dinero y medios (responsiones) para su lucha contra los sarracenos en Ultramar ${ }^{62}$, lo que fácilmente hubiera podido inducir valoraciones negativas y acusaciones de cobardía. Tales posibles valoraciones, fuera de la poesía profana, no son fáciles de documentar.

La explicación más sencilla al sentido de las referencias a la Orden de San Juan del Hospital en la poesía profana que nos ocupa es proponer que fueran un recurso literario un topos, un lugar común literario. Cabe otra, más compleja y discutible, en el sentido de que fuera una metonimia para designar a esa parte de la Iglesia y del clero alineado con los planteamientos políticos del papado en el contexto de la lucha güelfos-gibelinos, teniendo en cuenta el alineamiento básicamente gibelino de la corte castellano-leonesa, núcleo al que cabe asignar los escarnios contra la orden.

\footnotetext{
${ }^{59}$ Recordemos su poema Se me graça fezesse este Papa de Roma! (B463); o el escarnio de Airas Peres Vuiturom B1477, V1088.

${ }^{60}$ B1623/V1157 (C1623).

${ }^{61}$ BARQUERO GOÑI, Carlos - La Orden Militar de San Juan y la Reconquista desde el siglo XII hasta el siglo XV. Medievalismo. 22 (2013) 43-60.

${ }^{62}$ Ultramar aparece frecuentemente en la poesía galaico-portuguesa, siempre en un contexto de escarnio, bien como tema en sí mismo (B1584, V1116; B1586, V1118; B477; B477; B143 (C144); V1199; B1661, V1195; B1642, V1176; B1375, V983; B1598, V1130 y B1446, V1057) o en el contexto de las sátiras a Pero Garçía de Ambroa (V1004; B1456/V1066 y B1446/V1057). Es decir, fue un tema valorado negativamente en este contexto literario.
} 


\section{Conclusión: una hipótesis}

Resumiendo todo el decurso del poema, Vasco Gil y Alfonso X tratan de un asunto (preito) concreto, con un protagonista al que se califica de trajeitador, articulado a partir de un supuesto legal del ámbito de la jurisdicción civil procesal (la posesión y devolución alterada de un manto, manto que a su vez fuera un indicador de clase y señorío); con el añadido de contraponer la vieja legislación heredada (Livro de León) con la nueva (Decreta) estudiada en las escolas y por la que explícitamente se interesaba el rey. Este trajeitador innominado es comparado con um rei em Portugal quien houve um dia de trajeitar sabor y por ello hizo (a alguien) caballero del Hospital. Tenemos pues una clara comparación entre alguien, calificado abiertamente de trajeitador y un rey portugués así calificado.

El poema se articula sobre diversas contraposiciones, siendo la primera la que se establece en la primera estrofa entre posesión $\leftrightarrow$ devolución del manto; pasando seguidamente a Fuero de León $\leftrightarrow$ Decreta que conformará las dos siguientes estrofas; para terminar con otra mucho más difícil de entender que es la de ladrón $\leftrightarrow$ trajeitador (articulada a su vez sobre otra contraposición dual, a saber pena $\leftrightarrow$ cendal) que finalmente da paso a la comparación del innominado protagonista con um rei em Portugal.

Con esto acaba esta propuesta de la lectura del nivel literal y de la organización del poema, mas no profundizar sería traicionar a la misma idea de la literatura medieval, cuya hermenéutica y la explícita opción de la poesía profana galaico-portuguesa por las palavras cobertas, exige lecturas adicionales, con niveles más simbólicos.

Don Vasco Gil y Alfonso X enjuician negativamente un hecho, articulado sobre la idea básica de que, aunque no sea exactamente ilegal, supone una transformación no deseable. Al representar tal transformación en un manto, símbolo de posición social y asociado con el señorío (reforzado tal carácter al tener, o enriquecerse con, penas), la alteración puede interpretarse como un cambio en la situación de poder de la persona a la que critican. Esta alteración es similar a otra anterior, protagonizada por um rey em Portugal. Como dicho rey (¿se?) hizo caballero del Hospital, referencia literaria que pudiera ser un símbolo de la estructura eclesiástica en su conjunto, puede interpretarse que aquél rey portugués lejano transmutó 
su propia situación apoyándose en la Iglesia o en la Orden de San Juan; y que el innominado personaje criticado en la tenção habría hecho lo mismo.

Esto último permite presentar la hipótesis de que este personaje fuera Alfonso III de Portugal. Así, um rey em Portugal que originariamente trajeitou assi y aquel con quien se le compara sería don Afonso Henriques. Ambos reyes empezaron a ejercer el señorío no con categoría de reyes, sino que alcanzaron tal condición más tarde (modificaron la naturaleza de su señorío, de su manto, lo transformaron, trajeitaron) y en ambos casos fue esencial para ello el apoyo recibido de la estructura eclesiástica ${ }^{63}$. Podría interpretarse el último verso fez [se] cavaleiro do Hespital como una alusión al hecho de que el primer rey portugués enfeudara el reino al papado.

Esta hipótesis explica todos los elementos del poema, sin dejar apartados no comprobados independientemente. Así, Vasco Gil estaría pidiendo a Alfonso X su parecer sobre el cambio del estatuto real de Alfonso de Boulogne, convertido en rey a partir de la encomienda que Inocencio IV le hiciera de la gobernación del reino, y quiere saber qué dice al respecto la ley; el muy gibelino castellano-leonés le contesta que, habiendo estudiado leyes, sabe que no debe aceptar el señorío del reino de nadie ${ }^{64}$ (manto d'outrem nom filhe per rem ${ }^{65}$ ), pero que no es ilegítimo (o delictivo) mejorar aquello que de hecho se tiene; Vasco Gil responde que él de ninguna manera hizo tal acusación, pero que no obstante considera que Alfonso III ha transformado lo que tenía, y para calificar tal capacidad de transformación utiliza un término (trajeitador) con una evidente carga negativa; finalmente, Alfonso X cierra

${ }^{63}$ Afonso Henriques, no es cuestión de desarrollarlo aquí, mantuvo buenas relaciones con la Orden de San Juan de Jerusalén: un hijo ilegítimo suyo llegó a gran maestre de la Orden (CASTRO, Jose Ariel - Afonso de Portugal, $11^{\circ}$ grão-mestre da Ordem do Hospital de São João de Jerusalém, e o século XX português, Actas do III Congresso da Associação Internacional de Lusitanistas, Coimbra (1991), p. 819-848; http://www.reocities.com/Athens/ Crete/7424/afonso2.html).

${ }^{64}$ Todo el libro II del Espéculo y la II Partida están dedicados a este tema. Por abreviar, que las referencias son múltiples, baste la siguiente cita de la ley I del referido segundo libro del Espéculo: (Vol. I, p. 12-13) Por dos maneras queremos mostrar que cosa es rey. La una es spiritualmiente segunt las profetas e los santos. E la otra naturalmiente segunt los omes sabios e conoscedores de derecho.... Está claro que la apelación al derecho como base de la realeza concuerda con lo expresado en este poema.

${ }^{65}$ Verso que puede leerse tanto como: no se debe usurpar el señorío (manto) de otra persona; o, no debe aceptar que nadie le otorgue el señorío que sólo puede corresponderle por derecho. 
el poema recordando que lo que ha hecho Alfonso III no difiere demasiado de lo que hizo en su día, también con apoyo eclesiástico, Afonso Henriques, fundador de la dinastía y de la monarquía portuguesa.

Así, en otro nivel de interpretación, el poema se convierte en un manifiesto alfonsino sobre el carácter de la realeza, en la que cualquier alteración es sospechosa y rechazable. En la que el rey, por serlo, no debe ser puesto en cuestión como lo fue Sancho II por la nobleza y el episcopado rebelde, por muy apoyado que estuviera por el papado. Ello contravenía el orden natural de las cosas tal y como lo entendía la mentalidad alfonsí.

Esta lectura confirma la fecha propuesta en su día por Carolina Michaëlis, hacia 1252. Podría argumentarse a favor de una fecha algo anterior, pero el que Alfonso X fuera interpelado como rey lo impide. Esta temprana fecha es especialmente interesante, pues entonces el poema, dadas las referencias que contiene al Espéculo y las Partidas, se convierte en un testimonio relevante de lo que podríamos llamar el ambiente intelectual en el que se fraguó la gestación de la gran reforma alfonsí de la legislación hispana. 